\title{
Situating Vocational Learning and Teaching Using Digital Technologies - A Mapping Review of Current Research Literature
}

\author{
Martin Dobricki ${ }^{* 1}$, Alessia Evi-Colombo ${ }^{2}$, Alberto Cattaneo ${ }^{2}$ \\ ${ }^{1}$ Swiss Federal Institute for Vocational Education and Training, Learning Technologies \\ Research Group, Kirchlindachstrasse 79, 3052 Zollikofen, Switzerland \\ ${ }^{2}$ Swiss Federal Institute for Vocational Education and Training, Learning Technologies \\ Research Group,Via Besso 84, 6900 Lugano, Switzerland
}

Received: 01.11.2019, Accepted: 11.07.2020, Published: 02.12.2020

\begin{abstract}
Context: The ongoing change of work life by digital technologies requires vocational education and training (VET) to adapt constantly. This "digital transformation" of work life gives therefore rise to the question how to advance the use of digital technologies in VET. A possible answer may be found by considering that VET should be transferable to work life. This goal may be achieved by coupling educational activities with examples of work situations. Such situated education may be accomplished by using digital technologies. Until five years ago this mainly consisted in using digital photos, videos, and the internet for educational scaffolding or learning tasks. In research this situated digital VET taxonomy is currently expanding. Hence, the use of digital technologies in VET may be advanced by considering current research literature on situated digital VET.
\end{abstract}

Method: Here, we have searched and reviewed scientific publications on situated digital VET published in the past five years. In the peer-reviewed publications that we had selected, we first identified which digital technologies were used for situated VET and which educational activities were coupled with work situation examples. Subsequently, we identified the categories to which the publications could be grouped together by analyzing the content of their full texts.

${ }^{*}$ Corresponding author: martin.dobricki@ehb.swiss

ISSN: 2197-8646

http://www.ijrvet.net

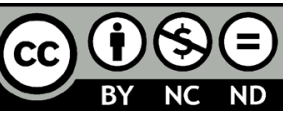


Results: Situated digital VET was accomplished in about half of the reviewed publications by a digital video on a work situation, and in almost half of the publications by a work situation presented in a 3D virtual environment. Digital videos on work situations mostly served all types of learning tasks and rather rarely educational scaffolding. Work situations presented in 3D virtual environments mostly served cognitive or behavioral learning tasks and never educational scaffolding. Situated digital VET was moreover accomplished by using the digital representation of a work situation that either had occurred previously or that was immediately taking place.

Conclusions: Our findings suggest that retrospectively and immediately situated digital VET may be the two categories of an up-to-date basic taxonomy of situated digital VET. Hence, an important question to investigate for advancing the use of digital technologies in VET is the following: Which of the two identified types of situated digital VET can facilitate which kind of vocational learning? Based on the reviewed publications we are not able to give any answers to this. Hence, there is a massive need to investigate which kind of vocational learning can be facilitated by retrospectively, and which by immediately situated digital VET.

Keywords: Situated Education, Situated Learning, Digital Technologies, Video, Hypervideo, 3D Virtual Environment, Literature Review, Vocational Education and Training, VET

\section{Introduction}

Digital technologies and their use are constantly changing work life in many professions (Harteis, 2018). This "digital transformation" of work life requires vocational education and training (VET) to adapt accordingly (Harteis, 2018; Latchem, 2017). Recent educational policies (Conrads et al., 2017) testify this necessity. For example, the Swiss State Secretariat for Education, Research and Innovation [SERI] (2017) published a document identifying the major challenges on which education and research should focus in order to cope with the digital transformation of work life. Two of the eight fields of action that SERI proposed for coping with these challenges concern improving the professional and educational use of digital technologies. One of the fundamental questions to which the digital transformation of work life gives rise is therefore how to advance the use of digital technologies in VET.

One of the main goals of VET is to prepare apprentices for their future work. Hence, what these vocational students learn through VET should be transferable to their work life. This goal may be achieved by coupling educational activities with examples of work situations (Boldrini et al., 2014; Kaiser, 2019). For example, clothing design students may be asked by their teacher to identify errors (Wuttke \& Seifried, 2012) in the sketch of a dress ordered by a real or imaginary customer. This is a simplified approach of situated learning and teaching 
(Lave \& Wenger, 1991), as it is optional if the work situations with which educational activities are coupled involve social interaction (Anderson et al., 1996). Such situated VET may be accomplished by exploiting the affordances (Bower, 2008) of digital technologies. Until about five years ago this mainly consisted in using digital photos, videos, and the internet for educational scaffolding or learning tasks (Schwendimann et al., 2015). In research this basic taxonomy of the use of digital technologies for situated VET is currently expanding. Learning tasks are for example coupled with work situations presented within "immersive" 3D virtual environments that spatially are including their viewer fully (Carruth, 2017; Schott \& Marshall, 2018). Hence, the use of digital technologies in VET may be advanced by considering current research on the use of digital technologies for situated VET. This would require to review the literature on this research. However, there is so far no such review. There is accordingly also no up-to-date basic taxonomy of the use of digital technologies for situated VET to which one could refer to. Here, we have therefore searched and reviewed current scientific publications on such situated digital VET. Stemming from the appraisal of the use of digital technologies in VET, this review seeks to explore the evidence regarding their use for situated teaching and learning in VET. The following three research questions guided this exploration: Which digital technologies are used for coupling educational activities with examples of work situations? Which are the educational activities that using digital technologies are coupled with work situation examples? What are finally the categories of an up-to-date basic taxonomy of situated digital VET?

\section{Method}

In accordance with the methodology proposed by Booth et al. (2016) we have accomplished a "mapping" review. The procedure of this descriptive review consisted in searching and selecting scientific articles published in the past five years, performing a descriptive synthesis of the selected articles, reporting this synthesis, and finally in discussing it. First, queries were performed in the digital literature databases named ERIC, Education Research Complete, PsycINFO, and IEEE Xplore. This was achieved by using the following combination of keywords: (("technolog*" OR "computational technolog*") AND "vocational education" AND ("learn*" OR "teach*")). Second, from the resulting set of abstracts those peer-reviewed publications were selected that were on (A) vocational education, (B) the use of digital technologies for coupling educational activities with examples of work situations, and which (C) involved results of empirical studies.

The procedure to select publications depicted in Figure 1 was as follows: The queries in the literature databases yielded for the past five years 1'985 publications. By reading the abstracts of these publications, the first author excluded 1'885 publications based on the criteria described in the previous paragraph. Subsequently, the other two authors checked which of 
the abstracts of the remaining 100 publications they judged to be eligible as well. The three authors then discussed the discrepancies of their abstract selections. Based on this discussion the authors decided to read the full texts of 40 out of the 100 publications picked initially by the first author. The three authors then discussed again which publications they judged to be eligible by taking their full text into consideration. Based on this discussion the authors decided to keep seventeen publications.

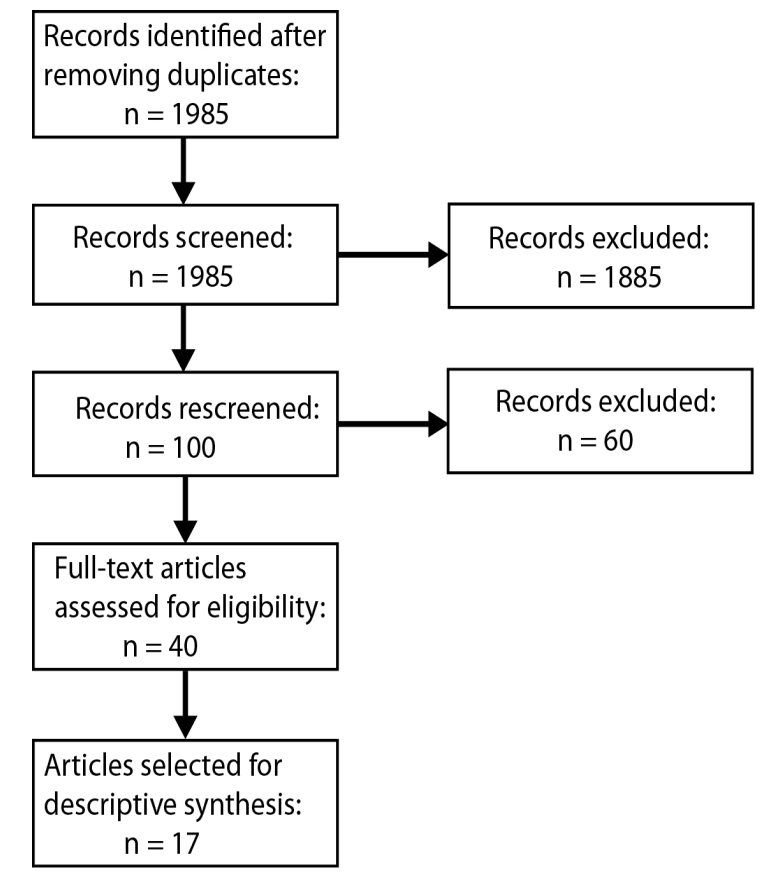

Figure 1: The Procedure to Select Publications for the Literature Review

The descriptive synthesis of the selected publications involved the following: The coding of the publications followed by its tabular and graphical presentation, a narrative synthesis of the selected publications and finally their thematic synthesis. The authors coded the publications of the final selection using the predefined coding scheme shown in Table 1. Most importantly, publications were coded regarding the work type (Lucas et al., 2012) and the educational activities that were coupled with examples of work situations, as well as regarding the digital equipment and digital media that were used for such situated education. The coded educational activities involved educational scaffolding (Hogan \& Pressley, 1997) and learning tasks. These tasks consisted in either cognitive, perceptual, or behavioral tasks. The cognitive learning tasks involved memorizing the parts of a work object, reflecting on a work process (Mann et al., 2009), and the treatment (Hmelo-Silver, 2004) or solving (Merriënboer, 2013) of a problem. Perceptual learning tasks involved the identification of errors 
(Wuttke \& Seifried, 2012), as well as the detection and discrimination (Kellman \& Garrigan, 2009; Seitz, 2017) of work objects. Behavioral learning tasks involved simple as well as complex motor action (Wolpert \& Flanagan, 2001), the collaboration with others (Dillenbourg, 1999), as well as educational games (Prensky, 2007) and the playing of professional roles. The coded digital media involved digital text, photo, video, as well as "hypervideo" (Sauli et al., 2018) and 3D virtual environments (Dalgarno \& Lee, 2010), which being presented with a head-mounted display (Carruth, 2017) were "immersive" (Dede, 2009; Slater et al., 2009), i.e., spatially including their viewer, or which being presented on a desktop display or tablet were "non-immersive", i.e., spatially excluding their viewer. In addition, the authors also coded the sample size investigated, and the research method used in the reviewed publications as well as the type of data that were collected.

Table 1: Coding Scheme

\begin{tabular}{ll}
\hline Variable & Coding \\
\hline Participants & Overall sample size \\
Work type & Profession mainly deals with: (1) Physical materials; (2) People; (3) Symbols \\
Research method & $\begin{array}{l}\text { (1) Case study; (2) Multiple case study; (3) Experimental study (4) Quasi-experimental } \\
\text { study; (5) Design-based research }\end{array}$ \\
Educational activity & (1) Cognitive learning task; (2) Perceptual learning task; (3) Behavioral learning task; \\
& (4) Educational scaffolding \\
Digital equipment & (1) Desktop display and computer; (2) Smart phone; (3) Tablet; (4) Digital camera; \\
Digital media & (5) Head-mounted display and computer \\
& $\begin{array}{l}\text { (5) Digital text } \\
\text { Collected data }\end{array}$ \\
& (1) Observations; (2) Interviews; (3) Questionnaire response; (4) Video-recordings; \\
&
\end{tabular}

The narrative synthesis consisted in summarizing the content of the selected publications. The subsequent thematic synthesis involved the analysis of the reviewed publications regarding their content. This analysis consisted in determining based on the differences and similarities (Aveyard, 2010) of the publications to which categories they could be grouped together. This content-based grouping of the publications served to identify the categories of a basic taxonomy of situated digital VET. 


\section{Results}

The result of the coding of the selected publications by the authors is summarized in Table 2 . Almost half of the publications involved single $(23.5 \%)$ or multiple $(23.5 \%)$ case studies. A bit more than half of the publications involved experimental $(29.4 \%)$ or quasi-experimental (23.5\%) studies. $11.8 \%$ of the publications involved design-based research. The digital technology used for situated VET most was the digital video (52.9\%), which includes the use of hypervideos (17.6\%). The second most used technology were the 3D virtual environments (47.1\%). The other technologies such as digital photos (23.5\%) and digital texts (11.8\%) were used less.

Table 2: Results of the Coding of the Seventeen Selected Publications

\begin{tabular}{|c|c|c|c|c|c|c|c|}
\hline Publication & $\begin{array}{l}\text { Overall } \\
\text { Sample }\end{array}$ & $\begin{array}{l}\text { Work } \\
\text { Type }\end{array}$ & $\begin{array}{l}\text { Research } \\
\text { Method }\end{array}$ & $\begin{array}{c}\text { Educational } \\
\text { Activity }\end{array}$ & $\begin{array}{c}\text { Digital } \\
\text { Equipment }\end{array}$ & $\begin{array}{l}\text { Digital } \\
\text { Media }\end{array}$ & Data \\
\hline Babu et al. (2018) & 26 & 1 & 3 & 1 & $1 ; 3 ; 5$ & 4 & 7 \\
\hline Cattaneo and Boldrini (2016) & 154 & 3 & 3 & $1 ; 2 ; 3$ & 1 & 2 & $3 ; 6$ \\
\hline Cattaneo and Boldrini (2017) & 180 & $1 ; 2$ & $1 ; 4 ; 5$ & $1 ; 2 ; 3$ & $1 ; 4$ & 3 & 3 \\
\hline Cattaneo et al. (2015) & 45 & 1 & 4 & 1 & 2 & 1 & $3 ; 7$ \\
\hline Cattaneo et al. (2016) & 72 & $1 ; 2 ; 3$ & 2 & $1 ; 2 ; 3 ; 4$ & $1 ; 4$ & 3 & $2 ; 3 ; 4$ \\
\hline Chen et al. (2017) & 62 & 1 & 3 & $2 ; 4$ & 3 & $1 ; 5$ & $3 ; 5$ \\
\hline Cubillo et al. (2015) & 44 & 1 & 3 & $1 ; 4$ & $1 ; 4$ & 3 & 3 \\
\hline Damasceno et al. (2017) & 41 & 1 & 4 & $1 ; 3$ & 1 & 4 & 5 \\
\hline $\begin{array}{l}\text { Hämäläinen and Cattaneo } \\
\text { (2015) }\end{array}$ & 39 & $1 ; 2 ; 3$ & 2 & $1 ; 3$ & $1 ; 2 ; 3$ & $1 ; 4 ; 5$ & $1 ; 4$ \\
\hline $\begin{array}{l}\text { Hämäläinen and Oksanen } \\
\text { (2014) }\end{array}$ & 30 & 2 & 5 & 3 & 1 & 4 & $1 ; 4$ \\
\hline Jose et al. (2016) & 12 & 1 & 2 & 3 & 1 & 4 & 5 \\
\hline $\begin{array}{l}\text { Lucignano and Dillenbourg } \\
\text { (2017) }\end{array}$ & 35 & 1 & 3 & $1 ; 2$ & 3 & $2 ; 4$ & 5 \\
\hline Motta et al. (2014) & 27 & 1 & 1 & $1 ; 3$ & 2 & 2 & 3 \\
\hline Pu et al. (2016) & 60 & 2 & 1 & $3 ; 4$ & 3 & $1 ; 2$ & $1 ; 2 ; 3$ \\
\hline Schild et al. (2018) & 24 & 2 & 2 & 3 & $1 ; 5$ & 4 & 3 \\
\hline Sirakaya and Cakmak (2018) & 46 & $1 ; 3$ & 4 & $1 ; 3$ & 2 & $2 ; 4$ & $1 ; 3 ; 7$ \\
\hline Sjöberg et al. (2015) & 6 & $1 ; 2$ & 1 & $1 ; 2$ & 4 & 2 & $1 ; 2 ; 4$ \\
\hline
\end{tabular}

Coding scheme: Overall sample: number of students. Work type: Profession mainly deals with: (1) physical materials; (2) people; (3) symbols. Research method: (1) case study; (2) multiple case study; (3) experimental study (4) quasi-experimental study; (5) design-based research. Educational activity: (1) Cognitive learning task; (2) perceptual learning task; (3) behavioral learning task; (4) educational scaffolding; Digital equipment: (1) Desktop display and computer; (2) smart phone; (3) tablet; (4) digital camera; (5) head-mounted display and computer. Digital media: (1) digital photo; (2) digital video; (3) hypervideo; (4) 3D virtual environment; (5) digital text. Data: (1) observations; (2) interviews; (3) questionnaire response; (4) video-recordings; (5) behavioral measure; (6) verbal annotations; (7) knowledge test. 
As shown in Figure 2, the educational activity that most often was coupled with the example of a work situation consisted in asking vocational students to engage in a cognitive task such as memorizing or reflecting. The second most coupled activity were behavioral tasks, which were followed by perceptual tasks.

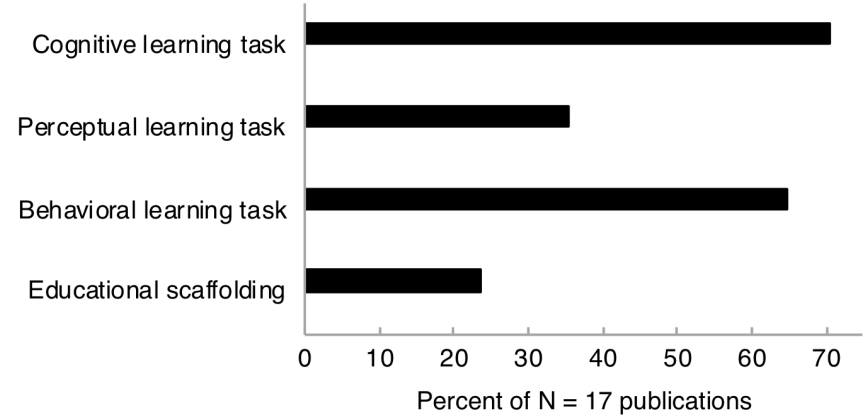

Figure 2: Educational Activities Coupled With Examples of Work Situations

As depicted in Figure 3, digital videos mostly served to couple cognitive, perceptual, or behavioral learning tasks and rather rarely educational scaffolding with work situation examples. The 3D virtual environments mostly served to couple cognitive or behavioral tasks, very rarely perceptual tasks, and never educational scaffolding with work situation examples. Digital photos were equally often used to couple work situation examples with a cognitive task, a behavioral task or with educational scaffolding. Digital text was equally often used to couple work situation examples with a cognitive task, a perceptual task, a behavioral task or with educational scaffolding.

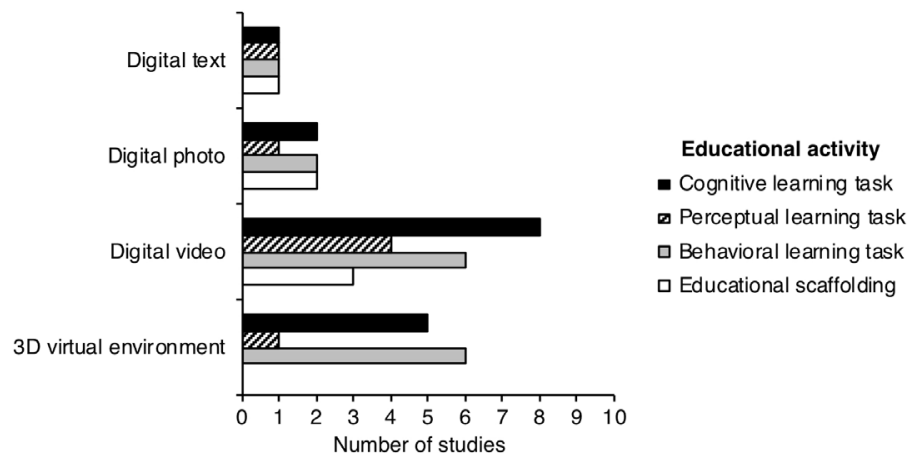

Figure 3: Digital Technologies Used for Situated VET 
The content analysis of the selected publications yielded the following: Digital technologies served to couple an educational activity with a work situation example in two different manners. They served to accomplish an educational activity with vocational students by using the digital representation of a work situation that either had occurred previously or that was immediately taking place. Hence, our analysis revealed a retrospectively and an immediately situated digital VET type.

As shown in Table 3, the retrospectively situated digital VET type emerged from the content-based grouping of seven publications. These publications involve studies in which digital technologies served to accomplish an educational activity for forming either procedural or declarative knowledge by using a past work situation. On one hand, this involved educating vocational students via digital representations of real or played work situations experienced by themselves. Motta et al. (2014) studied for example the training of car mechanics students through digital videos on a work procedure recorded by themselves with a head-mounted camera in a real work situation. Cattaneo et al. (2015) studied future cooks that were asked first to generate a digital recipe book using smartphone photos taken at their workplace and then to accomplish reflection tasks using their recipes. Sjöberg et al. (2015) studied the training of police students through their analysis of digital videos on themselves playing the role of a police officer in a critical situation. Similarly, Cattaneo and Boldrini (2016) studied the training of future office clerks through their identification of behavioral errors in digital videos on themselves playing the role of a vendor in a sales situation. On the other hand, retrospectively situated digital VET involved educating vocational students via digital representations of work situations experienced by others. Cattaneo and Boldrini (2017) studied for example the use of teacher-generated hypervideos on errors occurring during work procedures to educate various types of vocational students. Similarly, Cattaneo et al. (2016) studied, among other cases, the formation of knowledge on IT security by showing IT students a teachergenerated hypervideo on IT security at the workplace. Cubillo et al. (2015) finally studied the acquisition of knowledge on occupational health and safety by showing vocational students a teacher-generated hypervideo on work situations that were relevant for this topic.

As shown in Table 3, the immediately situated digital VET type emerged from the content-based grouping of ten publications. These publications involve studies in which digital technologies served to accomplish an educational activity for forming either procedural or declarative knowledge by using a work situation that was immediately taking place. On one hand, this involved educating vocational students via a mobile digital display in a real work situation. Pu et al. (2016) studied for example if a tablet-based mobile educational system of a nursing school could serve to form the skills of nursing students during their home visits of patients. 
Table 3: Content-Based Grouping of the Seventeen Selected Publications

\begin{tabular}{|c|}
\hline Retrospectively Situated Digital VET \\
\hline Cattaneo, A., \& Boldrini, E. (2016). Vocations and Learning, 10, 1-26. \\
\hline Cattaneo, A., \& Boldrini, E. (2017). Journal of Workplace Learning, 29(5), 357-373. \\
\hline Cattaneo, A., Motta, E., \& Gurtner, J.-L. (2015). International Journal of Mobile and Blended Learning, 7(3), 40-58. \\
\hline Cattaneo, A., Nguyen, A. T., \& Aprea, C. (2016). Journal of Educational Multimedia and Hypermedia, 25, 5-35. \\
\hline Cubillo, J., Martin, S., Castro, M., \& Boticki, I. (2015). Computer Applications in Engineering Education, 23, 778-789. \\
\hline Motta, E., Cattaneo, A., \& Gurtner, J.-L. (2014). Journal of Education and Training Studies, 2(1), 165-179. \\
\hline Sjöberg, D., Karp, S., \& Söderström, T. (2015). Journal of Vocational Education \& Training, 67(4), 529-542. \\
\hline Immediately Situated Digital VET \\
\hline $\begin{array}{l}\text { Babu, S., K., Krishna, S., Unnikrishnan, R., \& Bhavani, R. R. (2018). Proceedings of the IEEE International Conference on } \\
\text { Advanced Learning Technologies, 385-389. }\end{array}$ \\
\hline Chen, Y.-H., \& Wang, C.-H. (2017). Interactive Learning Environments, 26(5), 695-708. \\
\hline $\begin{array}{l}\text { Damasceno, E. F., Nardi, P. A., Silva, A. C. A., Dias Junior, J. B., \& Cardoso, A. (2017). IEEE Latin America Transactions, } \\
\text { 15(10), 1917-1925. }\end{array}$ \\
\hline Hämäläinen, R., \& Cattaneo, A. (2015). Vocations and Learning, 8(2), 135-157. \\
\hline Hämäläinen, R., \& Oksanen, K. (2014). Technology, Pedagogy and Education, 23, 81-101. \\
\hline $\begin{array}{l}\text { Jose, J., Unnikrishnan, R., Marshall, D., \& Bhavani, R. R. (2016). Proceedings of the International Conference on Robotics and } \\
\text { Automation for Humanitarian Applications, 1-6. }\end{array}$ \\
\hline $\begin{array}{l}\text { Lucignano, L., \& Dillenbourg, P. (2017). Proceedings of the IEEE International Symposium on Mixed and Augmented Reality, } \\
\text { Nantes, France, 137-142. }\end{array}$ \\
\hline Pu, Y.-H., Wu, T.-T., Chiu, P.-S., \& Huang, Y.-M. (2016). British Journal of Educational Technology, 47(3), 494-509. \\
\hline $\begin{array}{l}\text { Schild, J., Lerner, D., Misztal, S., \& Luiz, T. (2018). Proceedings of the IEEE International Conference on Serious Games and } \\
\text { Applications for Health, 1-8. }\end{array}$ \\
\hline Sirakaya, M., \& Cakmak, E. K. (2018). International Journal for Research in Vocational Education and Training, 5(1), 1-18. \\
\hline
\end{tabular}

Similarly, Chen et al. (2017) investigated if a tablet-based educational system of a gardening technology school could serve to form the skill of their students to discriminate between healthy and unhealthy plants in a botanical garden. On the other hand, immediately situated digital VET involved educating vocational students by exposing them to $3 \mathrm{D}$ virtual environments. Hämäläinen and Cattaneo (2015) studied if asking vocational students to play a work life-based game in a 3D virtual environment presented on a desktop display can serve to train them in collaborative problem solving. Further, Hämäläinen and Oksanen (2014) studied if teacher instructions were enhancing the inter-professional knowledge formation of vocational students playing a work life-based game in such a virtual environment. Damasceno et al. (2017) studied if presenting vocational students with a 3D virtual environment on a desktop display could serve to train the skill to install a computer network. Jose and colleagues (2016) studied if a sawing simulator consisting of a computer, desktop display and a haptic feedback device could serve to train vocational students in the motor skills needed to cut wood with different saw types. Lucignano and Dillenbourg (2017) studied if intermixing the real-time video of a physical miniature model of a rooftop with 3D virtual information on rooftop 
statics could serve carpentry students to learn such statics. Similarly, Sirakaya and Cakmak (2018) investigated if intermixing the real-time video of a computer motherboard with virtual information on its components and assembly could serve vocational students to learn how to correctly assemble such a work object. Schild et al. (2018) studied if treating a virtual human suffering a life-threatening emergency in a $3 \mathrm{D}$ virtual environment presented with a head-mounted display, could serve to train the skills of paramedic students. Finally, Babu et al. (2018) studied if vocational students could better memorize the parts of a motorcycle located in a $3 \mathrm{D}$ virtual environment when using a tablet or when using a head-mounted display for exploring this work object.

\section{Discussion}

Situated digital VET was accomplished in about half of the reviewed publications by a digital video on a work situation, and in almost half of the publications by a work situation presented within a 3D virtual environment. Digital videos on work situations mostly served cognitive, perceptual, or behavioral learning tasks and rather rarely educational scaffolding. Work situations presented in 3D virtual environments mostly served cognitive or behavioral learning tasks and never educational scaffolding. Situated digital VET was moreover accomplished by using the digital representation of a work situation that either had occurred previously or that was immediately taking place. This suggests that such retrospectively and immediately situated VET may be understood as the two categories of an up-to-date basic taxonomy of situated digital VET.

The Role of Digital Videos and 3D Virtual Environments for Situated Vocational Learning

Digital videos most often served retrospectively, whereas 3D virtual environments most often served immediately situated digital VET. Hence, it might appear that digital videos can only serve retrospectively, and 3D virtual environments can only serve immediately situated VET. This is, however, a wrong and misleading impression. On one hand, digital videos can serve immediately situated VET. Two of the reviewed studies (Lucignano \& Dillenbourg, 2017; Sirakaya \& Cakmak, 2018) were in fact on the educational use of intermixing the real-time video of a work object with virtual information on this object. Technically, it is moreover possible to record digital videos such that they can be presented in 3D. On the other hand, it is technically possible to capture a work situation presented in a 3D virtual environment including everything occurring within this environment as a 2D digital video. Studying the use of 3D virtual environments for retrospectively situated VET, or the use of 3D videos for immediately situated VET is accordingly possible. It is most probably just at the moment that no publications on such investigations can be found. Which digital technology can better serve to facilitate retrospectively situated VET and which immediately situated VET (Lin et 
al., 2012) is therefore a secondary question. The crucial question is which of the two types of situated digital VET accomplished by whatever digital technology can facilitate which kind of vocational learning. Based on the reviewed publications we are not able to give any answers to this. Hence, there is a massive need to investigate empirically which kind of vocational learning can be facilitated by retrospectively situated, and which by immediately situated digital VET. In light of our literature review, we hypothesize that the retrospectively situated digital VET type is serving more to facilitate the learning of the cognitive processing of, and the immediately situated VET type more the training of the behavioral skills for coping with a work situation. We moreover speculate that retrospectively situated digital VET is especially suitable for bridging work- and school-based learning in dual VET systems (Aprea \& Cattaneo, 2019; Cattaneo \& Aprea, 2018).

\section{The Spatial Human-Environment Relation Involved in Immediately Situated Digital VET}

Across the reviewed publications, we observed different manners to accomplish immediately situated digital VET. Vocational students were exposed either to a real or to an artificial work situation. The presentation of the artificial work situation was achieved in the following three manners: the real-time video of a work object intermixed with virtual information on this object was presented on a mobile display (Lucignano \& Dillenbourg, 2017; Sirakaya \& Cakmak, 2018), or a 3D virtual environment was presented either with a desktop (Hämäläinen \& Oksanen, 2014) or a head-mounted display (Babu et al., 2018; Schild et al., 2018). These different procedures for exposing vocational students to an artificial work situation do not result in the same spatial relation between the person viewing this situation and the environment in which it takes place. Depending on the procedure this "human-environment" relation (Heft, 2001) can be such that the environment in which a work situation occurs is spatially including its viewer fully. This is the case, when a work situation is taking place in a life-sized 3D virtual environment presented with a motion-tracked head-mounted display or in a real environment. It is, on the contrary, not the case, when the work situation occurs for example in a 3D virtual environment presented on a desktop display. Due to this differential spatial human-environment relation involved in the exposure to a real or artificial work situation a learner's perception and action in this situation may be quite different. For example, the $3 \mathrm{D}$ virtual environment in which a work situation is presented may be designed such that it enables a learner more or less, or not at all to explore this situation by walking around in it. The sensation of being "present" in such a virtual environment (Slater, 2009; Slater et al., 2009) may for this reason (Usoh et al., 1999) be differential as well (Makransky et al., 2017). None of the reviewed publications had studied anything like this. It is accordingly an open question if the spatial human-environment relation involved in the exposure to a real or artificial work situation is at all affecting vocational learning. Hence, investigating the role of the 
spatial human-environment relation involved in immediately situated digital VET might be regarded as an important avenue of future research.

\section{Using Augmented Reality Glasses for Situated Digital VET}

Among the reviewed publications there were no studies on using "Augmented Reality" glasses (Azuma, 1997; Milgram et al., 1994; Zarraonandia et al., 2019) for situated VET. Similar to the study of the educational use of 3D digital videos in VET it is most probably just at the moment that no publications on such studies can be found. It is nevertheless important to point out that Augmented Reality glasses may be very useful for situated VET. These glasses could serve for example vocational teachers to restructure their students experience of a problem (Ohlsson, 1984) in a real or artificial work situation through scaffolding. Such educational use of Augmented Reality glasses may thereby serve to educate future workforce in the professional use of this technology for "productive" (Ohlsson, 1984) instead of "reproductive" (Cunningham \& MacGregor, 2013) problem solving. It may moreover serve to transfer problem-solving skills (Hämäläinen et al., 2014) trained through a work situation presented within a 3D virtual environment in school to a real work situation. Hence, it appears to be worthwhile to study whether and how Augmented Reality glasses can be utilized for situated digital VET.

\section{Limitations}

Our review has the following main limitations. First, the amount of selected publications was rather low. About one third of these publications originated, moreover, from the last author's research group. The latter reflects the replicable fact that in international scientific journals very little empirical research on situated digital VET was published in the past five years. Thus, the reasons for identifying only few publications might have been our focus on English abstracts and our criterion that eligible publications had to involve empirical findings. Maybe not having this criterion and considering non-English abstracts the number of publications selected would have been larger. It is for example likely that the inclusion of German texts would increase the number of eligible publications considering the German VET tradition. However, it is important to point out that our overall impression is nevertheless that situated digital VET is a heavily under-researched field of study. A further limitation of our review is the level of detail of our coding scheme. We had opted for this scheme to be basic, as we were aiming at a basic taxonomy of situated digital VET. As a result, we had not coded the selected publications regarding less basic categories such as didactical design. Finally, an important limitation of our review is that only about half of the reviewed publications involved experimental or quasi-experimental studies. The other half of the publications were on multiple or single case studies. Thus, from a research methodology perspective one can state that the 
findings of about half of the reviewed papers were descriptive only. Single and multiple case studies are certainly valuable for the generation of hypotheses in the beginning of research. Yet, we conclude that currently there is a massive need for more experimental or quasi-experimental studies on situated digital VET.

\section{References}

Anderson, J., Reder, L., \& Simon, H. (1996). Situated learning and education. Educational Researcher, 25(4), 5-11. https://doi.org/10.2307/1176775

Aprea, C., \& Cattaneo, A. (2019). Designing technology enhanced learning environments in vocational education and training. In D. Guile \& L. Unwin (Eds.), Wiley International Handbook on Vocational Education and Training (pp. 373-394). Wiley. https://doi.org/10.1002/9781119098713.ch19

Aveyard, H. (2010). Doing a literature review in health and social care: A practical guide. McGraw-Hill.

Azuma, R. T. (1997). A survey of Augmented Reality. Presence: Teleoperators and Virtual Environments, 6(4), 355-385. https://doi.org/10.1162/pres.1997.6.4.355

Babu, S. K., Krishna, S., Unnikrishnan, R., \& Bhavani, R. R. (2018). Virtual reality learning environments for vocational education: A comparison study with conventional instructional media on knowledge retention. Proceedings of the IEEE International Conference on Advanced Learning Technologies (pp. 385-389). IEEE. https://doi.org/10.1109/ICALT.2018.00094

Boldrini, E., Ghisla, G., \& Bausch, L. (2014). Progetti di didattica per situazioni [Educational projects for situations]. In G. P. Quaglino (Ed.), Formazione. I metodi (pp. 337-360). Cortina.

Booth, A., Sutton, A., \& Papaioannou, D. (2016). Systematic approaches to a successful literature review (2nd ed.). Sage.

Bower, M. (2008). Affordance analysis - Matching learning tasks with learning technologies. Educational Media International, 45(1), 3-15. https://doi.org/10.1080/09523980701847115

Carruth, D. W. (2017). Virtual reality for education and workforce training. Proceedings of the 15th International Conference on Emerging eLearning Technologies and Applications (pp. 1-6). IEEE. https://doi.org/10.1109/ICETA.2017.8102472

Cattaneo, A., \& Aprea, C. (2018). Visual technologies to bridge the gap between school and workplace in vocational education. In D. Ifenthaler (Ed.), Digital workplace learning. Bridging formal and informal learning with digital technologies (pp. 251-270). Springer. https://doi.org/10.1007/978-3319-46215-8_14

Cattaneo, A., \& Boldrini, E. (2016). You learn by your mistakes. Effective training strategies based on the analysis of video-recorded worked-out examples. Vocations and Learning, 10, 1-26. https://doi. org/10.1007/s12186-016-9157-4

Cattaneo, A., \& Boldrini, E. (2017). Learning from errors in dual vocational education: Video-enhanced instructional strategies. Journal of Workplace Learning, 29(5), 357-373. https://doi.org/10.1108/ JWL-01-2017-0006

Cattaneo, A., Motta, E., \& Gurtner, J.-L. (2015). Evaluating a mobile and online system for apprentices' learning documentation in vocational education: usability, effectiveness and satisfaction. International Journal of Mobile and Blended Learning, 7(3), 40-58. https://doi.org/10.4018/IJMBL.2015070103 
Cattaneo, A., Nguyen, A. T., \& Aprea, C. (2016). Teaching and learning with hypervideo in vocational education and training. Journal of Educational Multimedia and Hypermedia, 25, 5-35.

Chen, M., Yu, S. Q., \& Chiang, F. K. (2017). A dynamic ubiquitous learning resource model with context and its effects on ubiquitous learning. Interactive Learning Environments, 25(1), 127-141. https://doi.org/10.1080/10494820.2016.1143846

Conrads, J., Rasmussen, M., Winters, N., Geniet, A., \& Langer, L. (2017). Digital education policies in Europe and beyond: Key design principles for more effective policies. In C. Redecker, P. Kampylis, M. Bacigalupo, \& Y. Punie (Eds.), EUR 29000 EN. Publications Office of the European Union. https://doi.org/10.2760/462941

Cubillo, J., Martin, S., Castro, M., \& Boticki, I. (2015). Preparing Augmented Reality learning content should be easy: UNED ARLE—an authoring tool for Augmented Reality learning environments. Computer Applications in Engineering Education, 23, 778-789. https://doi.org/10.1002/cae.21650

Cunningham, J. B., \& MacGregor, J. N. (2013). Productive and re-productive thinking in solving insight problems. The Journal of Creative Behavior, 48(1), 44-63. https://doi.org/10.1002/jocb.40

Dalgarno, B., \& Lee, M. J. W. (2010). What are the learning affordances of 3D virtual environments? British Journal of Educational Technology, 41(1), 10-32. https://doi.org/10.1111/j.14678535.2009.01038.x

Damasceno, E. F., Nardi, P. A., Silva, A. C. A., Dias Junior, J. B., \& Cardoso, A. (2017). 3D virtual simulation approach in Brazilian vocational education for computers network adapted to student knowledge. IEEE Latin America Transactions, 15(10), 1917-1925. https://doi.org/10.1109/ TLA.2017.8071236

Dede, C. (2009). Immersive interfaces for engagement and learning. Science, 323, 66-69. https://doi. org/10.1126/science.1167311

Dillenbourg, P. (1999). What do you mean by "collaborative learning"? In P. Dillenbourg (Ed.), Collaborative learning: Cognitive and computational approaches. Pergamon, Elsevier Science.

Hämäläinen, R., \& Cattaneo, A. (2015). New TEL environments for vocational education - Teacher's instructional perspective. Vocations and Learning, 8(2), 135-157. https://doi.org/10.1007/s12186015-9128-1

Hämäläinen, R., Cincinnato, S., Malin, A., \& De Wever, B. (2014). VET workers' problem-solving skills in technology-rich environments: European approach. International Journal for Research in Vocational Education and Training, 1(1), 57-80. https://doi.org/10.13152/IJRVET.1.1.4

Hämäläinen, R., \& Oksanen, K. (2014). Collaborative 3D learning games for future learning: Teachers' instructional practices to enhance shared knowledge construction among students. Technology, Pedagogy and Education, 23, 81-101. https://doi.org/10.1080/1475939X.2013.838451

Harteis, C. (2018). The impact of digitalization in the workplace. An educational view. Springer Nature. https://doi.org/10.1007/978-3-319-63257-5

Heft, H. (2001). Ecological Psychology in context. Erlbaum Associates.

Hmelo-Silver, C. E. (2004). Problem-based learning: What and how do students learn? EducationalPsychology Review, 16(3), 235-266. https://doi.org/10.1023/B:EDPR.0000034022.16470.f3

Hogan, K., \& Pressley, M. (1997). Scaffolding student learning. Instructional approaches \& issues. Brookline Books.

Jose, J., Unnikrishnan, R., Marshall, D., \& Bhavani, R. R. (2016). Haptics enhanced multi-tool virtual interfaces for training carpentry skills. Proceedings of the International Conference on Ro- 
botics and Automation for Humanitarian Applications (pp. 1-6). IEEE. https://doi.org/10.1109/ RAHA.2016.7931900

Kaiser, H. (2019). Situationsdidaktik konkret. Unterrichtsrezepte, Beispiele, Grundlagen [Situation didactics concrete. Teaching recipes, examples, basics]. HEP.

Kellman, P. J., \& Garrigan, P. (2009). Perceptual learning and human expertise. Physics of Life Reviews, 6, 53-84. https://doi.org/10.1016/j.plrev.2008.12.001

Latchem, C. (2017). Using ICTs and blended learning in transforming TVET. United Nations Educational, Scientific and Cultural Organization.

Lave, J., \& Wenger, E. (1991). Situated learning: Legitimate peripheral participation. Cambridge University Press. https://doi.org/10.1017/CBO9780511815355

Lin, J. M.-C., Wang, P.-Y., \& Lin, I.-C. (2012). Pedagogy * technology: A two-dimensional model for teachers' ICT integration. Britisch Journal of Educational Technology, 43(1), 97-108. https://doi. org/10.1111/j.1467-8535.2010.01159.x

Lucas, B., Spencer, E., \& Claxton, G. (2012). How to teach vocational education: A theory of vocational pedagogy. The City and Guilds Centre for Skills Development. https://doi.org/10.13140/2.1.3424.5928

Lucignano, L., \& Dillenbourg, P. (2017). Double Reality: Shifting the gaze between the physical object and its digital representation. Proceedings of the IEEE International Symposium on Mixed and Augmented Reality (pp. 137-142). IEEE. https://doi.org/10.1109/ISMAR-Adjunct.2017.50

Makransky, G., Terkildsen, T. S., \& Mayer, R. E. (2017). Adding immersive virtual reality to a science lab simulation causes more presence but less learning. Learning and Instruction, 60, 225-236. https://doi.org/10.1016/j.learninstruc.2017.12.007

Mann, K., Gordon, J., \& MacLeod, A. (2009). Reflection and reflective practice in health professions education: A systematic review. Advances in Health Sciences Education, 14(4), 595-621. https://doi. org/10.1007/s10459-007-9090-2

Merriënboer, J. J. G. (2013). Perspectives on problem solving and instruction. Computers \& Education, 64, 153-160. https://doi.org/10.1016/j.compedu.2012.11.025

Milgram, P., Takemura, H., Utsumi, A., \& Kishino, F. (1994). Augmented Reality: A class of displays on the reality-virtuality continuum. In H. Das (Ed.), Telemanipulator and telepresence technologies (pp. 282-292). SPIE. https://doi.org/10.1117/12.197321

Motta, E., Cattaneo, A., \& Gurtner, J.-L. (2014). Mobile devices to bridge the gap in VET: Ease of use and usefulness as indicators for their acceptance. Journal of Education and Training Studies, 2(1), 165-179. https://doi.org/10.11114/jets.v2i1.184

Ohlsson, S. (1984). Restructuring revisted. I. Summary and critique of the Gestalt theory of problem solving. Scandinavian Journal of Psychology, 25, 65-78. https://doi.org/10.1111/j.1467-9450.1984. tb01001.x

Prensky, M. (2007). Digital game-based learning. McGraw-Hill. https://doi.org/10.1145/950566.950567

Pu, Y.-H., Wu, T.-T., Chiu, P.-S., \& Huang, Y.-M. (2016). The design and implementation of authentic learning with mobile technology in vocational nursing practice course. British Journal of Educational Technology, 47(3), 494-509. https://doi.org/10.1111/bjet.12443

Sauli, F., Cattaneo, A., \& van der Meij, H. (2018). Hypervideo for educational purposes: a literature review on a multifaceted technological tool. Technology, Pedagogy and Education, 27(1), 115-134. https://doi.org/10.1080/1475939X.2017.1407357 
Schild, J., Lerner, D., Misztal, S., \& Luiz, T. (2018). EPICSAVE - Enhancing vocational training for paramedics with multi-user Virtual Reality. Proceedings of the IEEE International Conference on Serious Games and Applications for Health (pp. 1-8). IEEE. https://doi.org/10.1109/SeGAH.2018.8401353

Schott, C., \& Marshall, S. (2018). Virtual reality and situated experiential education: A conceptualization and exploratory trial. Journal of Computer Assisted Learning, 34, 843-852. https://doi. org/10.1111/jcal.12293

Schwendimann, B. A., Cattaneo, A., Zufferey Dehler, J., Gurtner, J.-L., Bétrancourt, M., \& Dillenbourg, P. (2015). The "Erfahrraum": A pedagogical model for designing educational technologies in dual vocational systems. Journal of Vocational Education \& Training, 67, 367-396. https://doi.org/10.10 80/13636820.2015.1061041

Seitz, A. R. (2017). Perceptual learning. Current Biology, 27, R623-R641. https://doi.org/10.1016/j. cub.2017.05.053

Sirakaya, M., \& Cakmak, E. K. (2018). Effects of Augmented Reality on student achievement and self-efficacy in vocational education and training. International Journal for Research in Vocational Education and Training, 5(1), 1-18. https://doi.org/10.13152/IJRVET.5.1.1

Sjöberg, D., Karp, S., \& Söderström, T. (2015). The impact of preparation: conditions for developing professional knowledge through simulations. Journal of Vocational Education \& Training, 67(4), 529-542. https://doi.org/10.1080/13636820.2015.1076500

Slater, M. (2009). Place illusion and plausibility can lead to realistic behaviour in immersive virtual environments. Philosophical Transactions of the Royal Society B, 364, 3549-3557. https://doi. org/10.1098/rstb.2009.0138

Slater, M., Lotto, B., Arnold, M., \& Sanchez-Vives, M. V. (2009). How we experience immersive virtual environments: the concept of presence and its measurement. Anuario de Psicologia, 40, 193-210.

Swiss State Secretariat for Education, Research and Innovation. (2017). Herausforderungen der Digitalisierung für Bildung und Forschung in der Schweiz [Challenges of digitisation for education and research in Switzerland]. State Secretariat for Education, Research and Innovation. https://www. sbfi.admin.ch.

Usoh, M., Arthur, K., Whitton, M. C., Bastos, R., Steed, A., Slater, M., \& Brooks, F. P. (1999). Walking > walking-in-place > flying, in virtual environments. Proceedings of the 26th annual conference on computer graphics and interactive techniques (pp. 359-364). ACM. https:/doi. org/10.1145/311535.311589

Wolpert, D. M., \& Flanagan, J. R. (2001). Motor prediction. Current Biology, 11(18), R729-R732. https://doi.org/10.1016/s0960-9822(01)00432-8

Wuttke, E., \& Seifried, J. (Eds.). (2012). Learning from errors at school and at work (Vol. 1). Budrich.

Zarraonandia, T., Díaz, P., Montero, A. 1., Aedo, I., \& Onorati, T. (2019). Using a Google glass-basedclassroom feedback system to improve students to teacher communication. IEEE Access, 7, 1683716846. https://doi.org/10.1109/ACCESS.2019.2893971 


\section{Biographical Notes}

Dr Martin Dobricki is a senior scientist in the learning technologies research group at the Swiss Federal Institute for Vocational Education and Training. His research is focused on the empirical study of vocational learning and teaching using immersive Virtual Reality technology.

Alessia Evi-Colombo, MSc is a $\mathrm{PhD}$ candidate in the learning technologies research group at the Swiss Federal Institute for Vocational Education and Training. Her research is focused on the study of vocational learning and teaching using digital videos and hypervideos.

Prof Dr Alberto Cattaneo is the head of the learning technologies research group at the Swiss Federal Institute for Vocational Education and Training. His research is focused on the study of the educational use of novel digital technologies for vocational learning and teaching. 